\title{
Giuseppe Marcenaro, Una sconosciuta moralità. Quando Verlaine sparò a Rimbaud
}

\section{Damiano Sinfonico}

\section{(2) OpenEdition}

1 Journals

\section{Edizione digitale}

URL: http://journals.openedition.org/studifrancesi/2239

DOI: 10.4000/studifrancesi.2239

ISSN: 2421-5856

\section{Editore}

Rosenberg \& Sellier

\section{Edizione cartacea}

Data di pubblicazione: 1 aprile 2014

Paginazione: 175

ISSN: 0039-2944

\section{Notizia bibliografica digitale}

Damiano Sinfonico, « Giuseppe Marcenaro, Una sconosciuta moralità. Quando Verlaine sparò a Rimbaud ", Studi Francesi [Online], 172 (LVIII | I) | 2014, online dal 01 avril 2014, consultato il 18 septembre 2020. URL : http://journals.openedition.org/studifrancesi/2239 ; DOI : https://doi.org/10.4000/ studifrancesi.2239

Questo documento è stato generato automaticamente il 18 settembre 2020.

\section{(c) 9 (i) $\Theta$}

Studi Francesi è distribuita con Licenza Creative Commons Attribuzione - Non commerciale - Non opere derivate 4.0 Internazionale. 


\title{
Giuseppe Marcenaro, Una sconosciuta moralità. Quando Verlaine sparò a Rimbaud
}

\author{
Damiano Sinfonico
}

\section{NOTIZIA}

GIUSEPPE MARCENARO, Una sconosciuta moralità. Quando Verlaine sparò a Rimbaud, Milano, Bompiani, 2013, pp. 327.

1 Dire che Giuseppe Marcenaro è un gaudente erudito lanciato in scorribande letterarie, che raccoglie le tracce degli artisti per collezionarle in un ideale museo dei più venerati autori, che racconta le sue ricerche in libri sempre raffinati, sarebbe riduttivo. Marcenaro è, ai nostri occhi, uno scrittore. È uno che racconta e sa dove tagliare corto, concludere, sigillare con una nota o una malizia, liquidare un personaggio o prenderlo per il verso giusto; una sua specialità è la cesura: in questo libro, massima quella tra il capitolo sesto e il settimo, dove la parossistica vicenda tra Verlaine e Rimbaud viene abrasa via, sottaciuta nel passaggio tra l'arrivo dei due poeti a Bruxelles e l'arresto di Verlaine, perché quei due spari sono già raccontati altrove, in apertura del libro, a pagina uno. L'evento catalizzatore che origina l'intera storia e la tramuta in leggenda, è spiattellato fin da subito, con un trucco: i nomi dei due protagonisti sono rivelati solo alla terza pagina, sovrapponendosi agli ingiuriosi epiteti di girovaghi e ubriaconi. Due signori nessuno agli occhi dell'albergatore e della polizia, due sconosciuti la cui fama di poeti non li accompagna e non li salva, condannati a essere persone giuridiche ordinarie, da sottoporre per protocollo a pratiche umilianti come una visita medica alquanto invadente.

2 L'evento centrale dà allo scrittore l'occasione di percorrere in più dimensioni una storia che si allarga come tanti cerchi concentrici attorno a figure altrimenti rimaste nell'ombra, abbandonate al loro destino se non fosse per quei minuti in cui hanno 
incrociato le vie di due poeti. L'autore si dipana in innumerevoli aneddoti, storie secondarie che convergono tutte verso il fattaccio di rue de Brasseurs: marginalità collaterali o postume che vedono per protagonisti personaggi, oggetti e luoghi che hanno attraversato burrascosamente o scialbamente l'eredità o l'aldilà di Verlaine e Rimbaud. Storie di alberghi, giudici istruttori, suoceri, amici d'infanzia, ma anche prime edizioni, lettere, album, ritratti... tutti si ritrovano in un pulviscolo attraversato dalla stessa luce torbida che ha visto muoversi nell'accecante passione le gesta dei scapestrati girovaghi.

Ricorrente, nella costruzione del libro e nella narrazione della vicenda, la metafora teatrale: la storia è troppo golosa per non lasciarsi trattare come una pièce i cui attori hanno un momento di gloria e poi sono riassorbiti nel buio dell'anonimato. Attorno ai due grandi poeti, una folla di comprimari si inseriscono a vario titolo negli interstizi lasciati vuoti; così anche i verbali del processo, la tessera d'iscrizione di Rimbaud alla British Library, un mazzo di fiori di Fantin-Latour hanno una storia da raccontare.

4 Ammessa la puntuale e minuziosa veridicità del racconto, trascurata la domanda se la lettura di Una sconosciuta moralità arricchisca la comprensione delle opere dei due poeti, un'altra riflessione preme: se tra persona e autore ci sia coincidenza, se le avventure biografiche siano in relazione con i tesori poetici. Il nome che appare sulle cartelle di un processo giudiziario è lo stesso che appare sulla copertina di un libro? Sì, evidentemente. Se i due nomi sono gli stessi, se la persona che ha sparato all'amico è la stessa che ha partorito Romances sans paroles, perché non avvolgere le sue gesta nell'alone romantico del poeta maledetto? Dove sta la differenza e insieme l'equivoco che consente di unire il fascino per il poeta al fascino per la persona, l'emozione per un verso all'emozione di un nome scritto su un cartoncino burocratico?

5 I teorici più avvertiti si sono avvitati intorno a questo problema, con tanto di dogmi e sistemi da sbandierare. Michel Foucault squadernò il problema nella celebre conferenza del febbraio 1969, Che cos'è un autore? Discutibile e sofisticata, la prospettiva di Foucault può essere la lucida compagna di una lettura che vede per protagonista un poeta non nell'atto di scrivere ma di amoreggiare: da una parte i fatti della vita, aggregati, inanellati e spiegati con il nome della persona giuridica; dall'altra parte i fatti letterari, costituiti a sistema sotto il cappello del nome d'autore. 